\title{
The Application of Corporate Image in the Design of the Holiday Inn Express Pluit Citygate Hotel Lobby
}

\author{
Amelia Putri ${ }^{1}$ Franky Liauw ${ }^{2}$ Maitri W. Mutiara ${ }^{*}$ \\ ${ }^{1}$ Faculty of Fine Arts and Design, Universitas Tarumanagara, Jakarta, Indonesia \\ ${ }^{2}$ Architecture Department, Universitas Tarumanagara, Jakarta, Indonesia \\ *Corresponding Author. Email: maitrim@fsrd.untar.ac.id
}

\begin{abstract}
A hotel is an establishment that provides paid lodging on a short-term basis, which is now also in great demand by people as a means of recreation. The lobby is a room where guests arrive when they first arrive at the hotel. First impressions are a vital aspect for hotels and companies to attract visiting guests. Appropriate and attractive implementation can attract hotels to attract customers to visit the hotel. Thus, designing a hotel that can reflect the brand image is necessary and will provide guests with an unforgettable experience. The right brand image will increase the loyalty of visitors who come and visit the hotel. Therefore, corporate image and its application to the interior are vital to guests' satisfaction and experience visiting the hotel. The objective of the interior design planning is to design the lobby's interior that reflects the brand image and gives the experience to the guests. The design method used is the design process by Rosemary Kilmer, divided into two stages, namely the analysis phase (programming stage), and the synthesis stage (designing stage). The concept applied in this interior is a contemporary style combined with Indonesian-Nature-themed interior touches. This design is expected to welcome the guests, experience genuine hospitality, and gives them an unforgettable experience from any other hotels.
\end{abstract}

Keywords: Brand, Image, Hotel, Interior, Lobby

\section{INTRODUCTION}

Business Hotels are hotels whose main facilities can accommodate all business activities and guests' activities visiting the hotel. Therefore, business hotels are generally located in ideal locations, in the centre or near the city centre. The number of executives who travel on business today inspires us on making innovations continue to emerge. One form of innovation is to combine business activities with vacation. Hence, the hotel's function is essential as a means of recreation and education for visitors who come and stay.

A lobby is a terrace space near the building entrance, which is usually equipped with various tables and chairs, which function as a sitting room or waiting room. Some research has been done to develop scales to measure the lobby atmosphere to improve hotel lobby design to create the right impression and convey an image.

According to KBBI, an image is an expression, description, or visualization of everything objectively known, an impression, an individual or a group's presumptions regarding a tourist destination regarding culture, natural beauty, and handicrafts certain tourist areas. Brand image or what is known as the corporate representation image can affect customers in customer loyalty, hotel quality, and customer trust in a brand [1]
The entry of an office and the reception area are important design features that can project immediate impressions about the company and its interior spaces. The image of the firms is often set at this front entrance. Entries are usually designed around several functions that serve both visitors and staff [2].

The large number of hotels established has increased the competition in maintaining and attracting new customers. Marketers believe that the relationship that exists between the seller (hotel party) and the buyer (hotel guest) in the future depends on the level of loyalty of the customers themselves. To increase loyalty can occur because the company has an excellent product image [3].

The interior design is essential for creating the creative and technical solutions that are functional, balancing the quality of life and culture of the user, and aesthetically attractive. A good interior design of the office lobby should reflect the overall corporate branding.

Creating a design concept that can reflect the brand's identity is essential because it will affect the hotel system and performance.

The lobby, which is the main door for a customer to come to the hotel, is an important place to welcome customers to deliver an excellent first impression. 
So, the authors want to design a hotel lobby that reflects the company's image and show how a company's image influences interior design.

\section{METHODS}

The method used in this design is the design process from the book Designing Interiors by Rosemary Kilmer. The design method according to Kilmer [2] is divided into two stages, namely the analysis phase which aims to identify problems, understand, and analyze problems, and the second is the synthesis stage carried out to process the results of problem analysis into a solution that can be applied to the design [2].

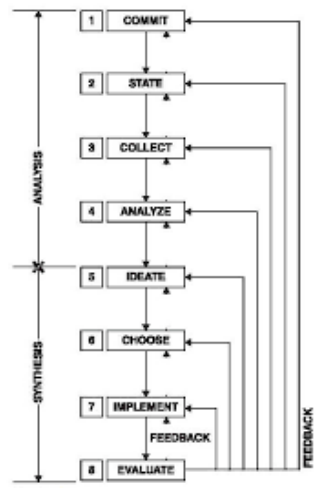

Figure 1 Design Process Diagram

(Source: Rosemary Kilmer and Otie Kilmer, 2014)

In this design, the analysis phase is the programming stage where the writer gathers all the data related to the project design process, and then the synthesis phase which is a designing process that aims to produce solutions to problems obtained from the previous stage.

The stages in this design method are:

A. Commit, the initial stage to accept and commit to this project, the author has committed to the Holiday Inn Express Pluit City gate project.

B. State, the stage for defining project problems.

C. Collect, the data collection stage connects with the design process in this design, namely, surveys and site observation.

D. Analyze, the stage for analyzing problems in the project outlined in the report.

E. Ideate, the stage of generating ideas or thoughts that are useful to solve the project's problems in this project, namely circulation and space organization and a friendly atmosphere.

F. Choose, the aim is to choose ideas or thoughts that are suitable for use in the project. Several ideas were used, such as dove hanging lights and metal flower artwork, based on the references.

G. Implement, it is useful to channel ideas through either 2D or $3 \mathrm{D}$ presentations. For $2 \mathrm{D}$, AutoCAD and $3 \mathrm{D}$ software use manual rendering and digital rendering.

H. Evaluate, this stage aims to review the design that has been produced.

\section{RESULTS AND DISCUSSIONS}

\subsection{Concept}

Images cannot be implanted in people's minds overnight or spread through the mass media. On the contrary, the image must be conveyed through every available means of communication and disseminated continuously. To succeed in acquiring and retaining its consumers, every company must make every effort to present its products by having a positive brand image in consumers' eyes. By displaying products that have a positive brand image can enhance consumer confidence in their products and encourage consumers to become loyal consumers.

Based on the vision and mission that prioritizes hospitality. Holiday Inn Express Pluit Citygate is a place that has a unique attraction for its visitors. Upholding hospitality is one aspect of consideration in designing. The meaning of friendly at KBBI is "kind-hearted and attractive language; sweet speech and attitude. "Means friendly is an action that shows politeness and a warm welcome, such as smiling, greeting and not hurting [4].

This friendly word can be translated into a form and interior aspect of the design process. Friendly can be defined as being open or closed, welcoming, attractive, not dull and not hurting. From these words, it can be translated into an open space; the designed room must also attract attention to welcome the guests who come and lastly not hurt.

The basic principle of an open plan is a space that is not entirely closed or separate [5]. Open space can be interpreted as an open interior arrangement from one room to another to get a spacious and fresh impression, which means that the room's air circulation can flow smoothly without being obstructed by walls or dividers. An attractive and aesthetic design is needed to attract visitors. Besides, it can also give visitors the impression to remember the place. According to KBBI, hurt it is "Causing pain (sadness, misery); hurts. " So, not hurting means not causing pain and not hurting [6].

The Vision and Mission of the Holiday Inn Express Pluit Citygate Hotel is True Hospitality for everyone. They believe in making guests feel welcome and valued wherever in the world. The Holiday Inn Express offers tourists excellent service and modern facilities at an exceptional value. They are using Green Engage for innovative environmental systems to manage environmental impacts. From the vision and mission of Holiday Inn, the brand image that Holiday Inn Express Jakarta wants to represent are Multicultural, Hospitality, Earth and Fun. The brand image determined is related to the location, activities, visitors and the hotel institution itself.

The Holiday Inn Express Jakarta interior design is inspired by its image, namely the word "Friendly" which does not hurt and the location of the hotel, which is a place to introduce Indonesian culture to outsiders. Inspired by not hurting, of course, we do not want to hurt our environment either.

Thus, using a theme from nature is one of the actions that can be used because natural resources are natural resources 
that can be renewed by the environmental system implemented by Holiday Inn Hotels.

Indonesia, A land full of diverse cultures, known for its languages and tourist attractions, provides interesting elements towards the hotel's interior design. It is a pride to have a culture from many aspects such as music, art and, pattern. Not to mention the beauty of Indonesia's natural charm that was created by the universe.

With these considerations, the Holiday Inn Express Pluit Citygate's interior design adopts the "GAIA" concept, meaning Goddess of Earth. Ruler of the earth and the universe. Has a concept where every aspect of the room uses elements from the earth and applies it to interior design.

In order to create a reflective lobby interior the image of hospitality, the author applies several translations of the word friendly into elements of designs [7] such as:

\section{Line}

Horizontal and vertical lines on tables and other surfaces give a stable, formal and efficient impression. Interior designers highlight horizontal stripes to make the room appear wider or longer and direct the eye to essential room elements. To be balanced, it will be combined with curved lines that give the impression of beauty, joy and luxury to create a good interior design.

\section{Colour}

The colours used in the Holiday Inn Express Pluit will be dominated by neutral colours such as brown, white, green and complemented by accent colours such as blue and yellow which symbolize the logo's characteristics.
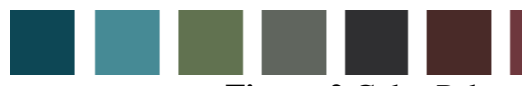

Figure 2 Color Palette

(Source: Personal Data, 2020)

\section{Scale}

The scale is a fun measurement system (measuring tool); it can be in $\mathrm{cm}$, an inch, or whatever units to be measured. The scale is determined not only by the activities carried out in the building but also by the number of people who participate in these activities. in interior design, the human scale becomes the benchmark in standardizing space. Therefore, the Holiday Inn Express Pluit Hotel's interior design will use the standards in the book "Time Saver Standard".

\section{Material}

The materials used are natural materials such as wood, natural stone, rattan and water. The materials chosen are materials that can last a long time and are low maintenance and sustainable. The hospitality of IHG Green Engage from the hotel is achieved, an environmental sustainability system to protect the surrounding environment.

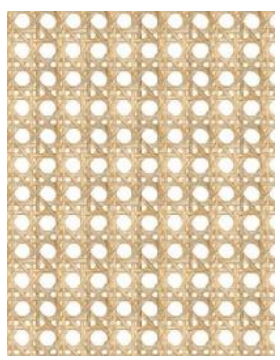

Figure 3 Material Concept

(Source: Personal Data, 2020)

\subsection{Results}

Gaia, the goddess of the earth and the mother of nature, has become the whole hotel's central concept. Inspired by the gardens from nature, the lobby area concept is Serene Garden. This room will welcome the guests who visit. The lobby reflects this hotel itself, so the author wants to design the hotel lobby to match Holiday Inn Express Jakarta's image and theme, which reflects Hospitality.

Gardens are wonderfully peaceful places. It is so great to stroll, feeling comfortable and welcome in the Garden - the sound of water and calm. We want our guest to feel welcomed when they arrived at the lobby of the hotel. Not only the first impression on the interior but also the experience they could get at the hotel. These are the main ideas for the interior.

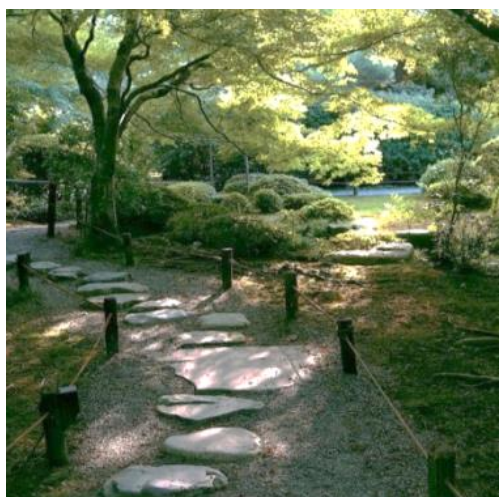

Figure 4 Garden

(Source: Kyoto Garden, 2020)

The interior will combine wood-inspired materials, marbles, and decorative elements that represent nature; besides being eco-friendly, the materials also used sustainably. While the colours used are neutral and earth tone colours. To be able to complement the design and theme. Blue, the company logo, will be used as an accent colour to show the company image in interior applications. The aesthetic elements used are inspired by the beauty of nature, where birds fly and roam freely. As in for this, pigeons are chosen as the aesthetic implementation for the interior. Pigeons, birds that symbolize peace, tranquillity. Pigeons will be applied to lights like they were flying in the air. They will be equipped with the latest technology to give a light show for the guests while waiting at the lobby. The 
implementation of pigeons as hanging lights are not merely aesthetic purposes but also give the guests the extra experience they will not get at any other hotel.

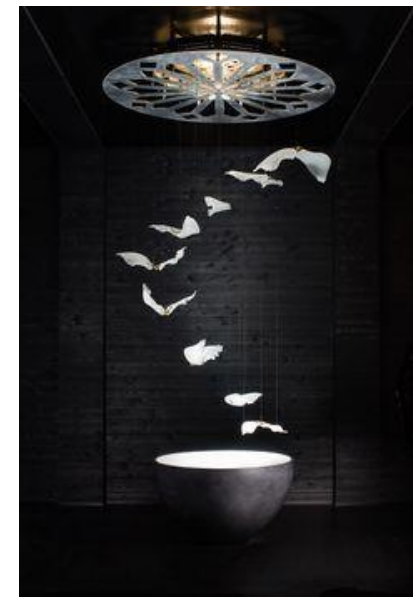

Figure 5 Hanging Lights

(Source: Preciosa, 2016)

Metal artwork will be used to make a highlight on the reception wall. The metal artwork is a new type of artwork other than paintings and pictures. The artwork will give a modern and unique feel to the interior design.

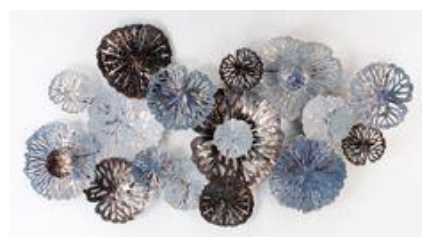

Figure 6 Metal Flower Artwork

(Source: Betaalbare kunst, 2020)

The furniture used will use natural materials such as wood and stone. The selection of furniture is seen from comfort, function, and durability to meet the hotel's sustainability. Visitor comfort is prioritized in furniture selection. The furniture chosen is contemporary furniture that combines traditional elements with modern aspects. The guests who visit can feel the nuances of Indonesian and Modern culture to match the current trend.

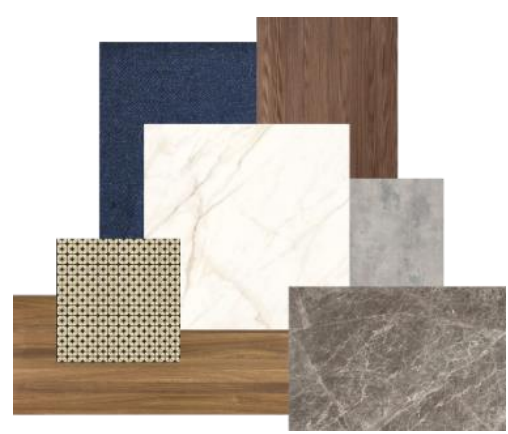

Figure 7 Material Scheme

(Source: Personal Data, 2020)
The materials chosen were natured inspired. Natural stones such as marbles will be used as the flooring material for the lobby area. Various types of marbles were used in the design process to enhance the look. Wood was mainly used as the room's primary material, bringing warmth and the garden feel to the room.

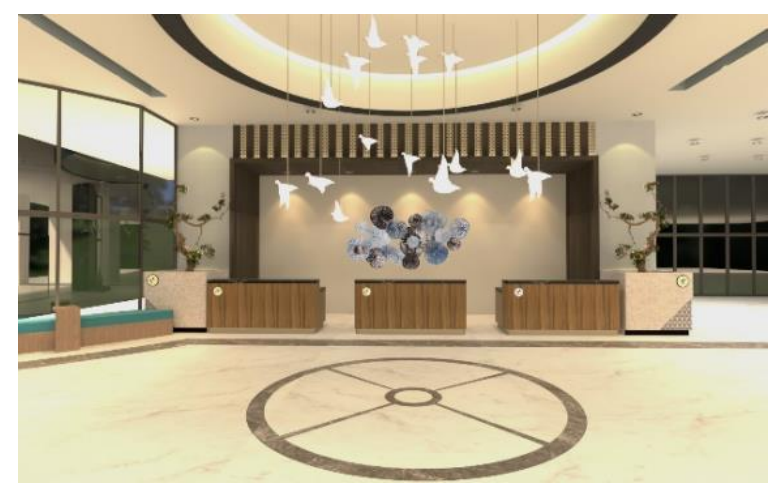

Figure 8 Perspective View 1

(Source: Personal Data, 2020)

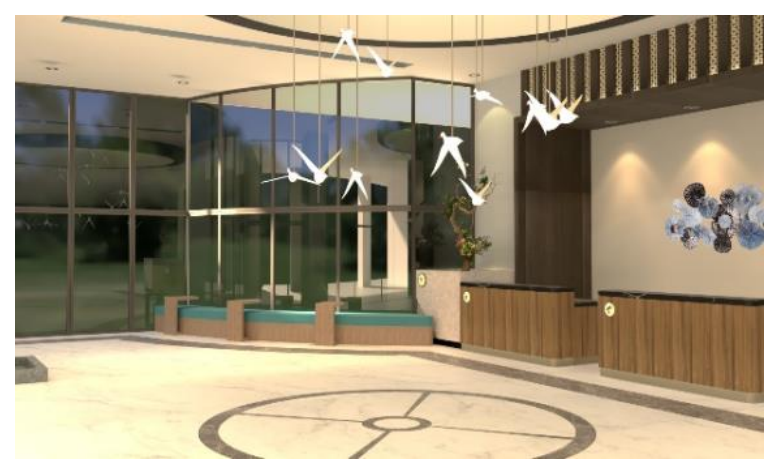

Figure 9 Perspective View 2

(Source: Personal Data, 2020)

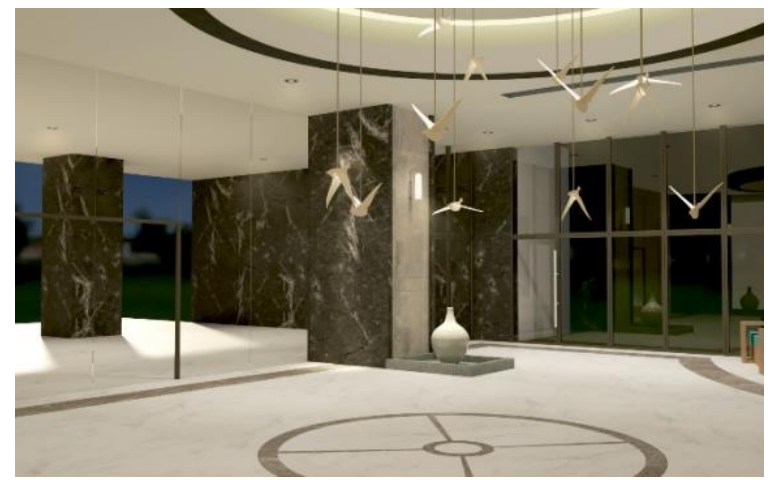

Figure 10 Perspective View 3

(Source: Personal Data, 2020)

These are some perspective pictures of implementing the image into the interior of the Holiday Inn Express hotel's lobby.

The first impression is the most crucial aspect of visiting guests. The first impression is the author's primary consideration in designing and designing the Lobby space at the Holiday Inn Express Pluit Citygate hotel. When 
visitors enter the lobby, they will be greeted with a hanging lamp in the shape of a dove, which is the room's focal point. The dove brings peace and tranquility. It is an implementation of friendly, harmlessness.

This lamp is also equipped with a driving engine to move when it is turned on. In addition to the interior and aesthetic function application, designers also want to design to provide guests with experience. The lamp is equipped with kinetic lights technology, where the lights can rotate and be accompanied by music.

The metal flower art in the lobby also reminds us of the lobby theme, namely Serene Garden. Flowers are used as a translation of the garden where flowers are usually found. At the same time, blue is chosen as an accent colour to display the company logo's colour.

The water fountain located near the entrance is put to enhance the beauty of nature. The designers want to emphasize serene's feel so that the sound of trickling water can be heard in the lobby.

Finally, all the materials used in this room come from natural stone and wood to maintain the image of a company that uses a green engage system to use sustainable and ecofriendly materials.

\section{CONCLUSIONS}

Based on this research, it can be stated that the implementation of brand images in interior design has a strong correlation so that the need for an interior design that can reflect the company's identity is essential. The brand image can be translated into the interior, atmosphere, colour, and impression that the visitor gets. The better the translation of the image in the interior, the higher the customer satisfaction and trust level. The proper implementation is also a unique attraction for hotel interiors that differentiates it from other hotels.

This study still has limitations in carrying out interior design due to the current pandemic situation that does not allow the author to conduct an in-depth survey hotel. The author suggests using new ideas and ways of implementing images in the interior with a new perspective

\section{ACKNOWLEDGMENT}

The author would like to thank all those who helped write this research to be carried out and finished on time.

The author wants to thank:

1. Mr. Leo, as the manager of Holiday Inn Express who have been willing to guide and provide information for the writer.

2. Parents who have given full support.

3. All parties who have helped this Final Project report that cannot be mentioned one by one.

\section{REFERENCES}

[1] Setiawan. (n.d.). Retrieved from Kamus Besar Bahasa Indonesia (KBBI): https://kbbi.web.id/citra

[2] Kilmer, R., \& W, O. (2014). Designing Interiors. New York: Wiley.

[3] Mutiara, M. W. (2015). Analyzing the Impact of Corporate Value on Space Design, Case Study: Main Lobby of Universitas Tarumanagara.

[4] Setiawan. (n.d.). Retrieved from https://kbbi.web. $\mathrm{id} /$ ramah

[5] Ching, F. D. (2008). Arsitektur, Bentuk, Ruang, dan Tatanan. Jakarta: Erlangga.

[6] Setiawan. (n.d.). Retrieved from Kamus besar Bahasa Indonesia (KBBI): https://kbbi.web.id/sakit

[7] Maitland, G. (2019). Art of Color and Design. S.1. : Echo Point Books \& Media. 